\title{
Overview of Chamber and Target Technology R\&D for Heavy Ion Fusion
}

\author{
W.R. Meier
}

This article was submitted to $13^{\text {th }}$ International Symposium on Heavy Ion Fusuon, San Diego, CA, March 13-17, 2000

\section{March 2000}

U.S. Department of Energy

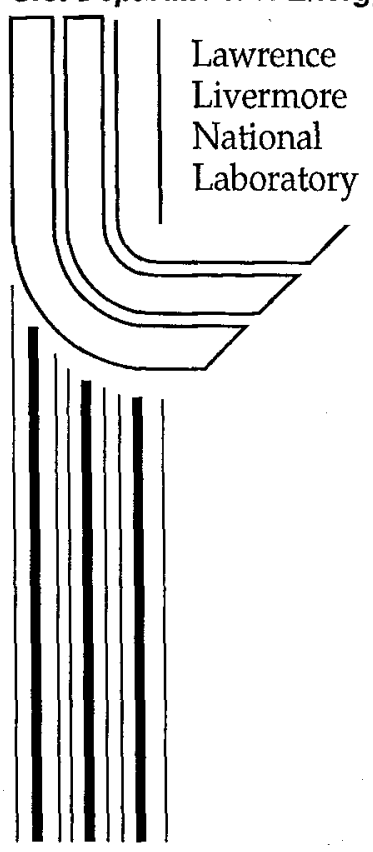




\section{DISCLAIMER}

This document was prepared as an account of work sponsored by an agency of the United States Government. Neither the United States Government nor the University of California nor any of their employees, makes any warranty, express or implied, or assumes any legal liability or responsibility for the accuracy, completeness, or usefulness of any information, apparatus, product, or process disclosed, or represents that its use would not infringe privately owned rights. Reference herein to any specific commercial product, process, or service by trade name, trademark, manufacturer, or otherwise, does not necessarily constitute or imply its endorsement, recommendation, or favoring by the United States Government or the University of California. The views and opinions of authors expressed herein do not necessarily state or reflect those of the United States Government or the University of California, and shall not be used for advertising or product endorsement purposes.

This is a preprint of a paper intended for publication in a journal or proceedings. Since changes may be made before publication, this preprint is made available with the understanding that it will not be cited or reproduced without the permission of the author.

This report has been reproduced directly from the best available copy.

Available to DOE and DOE contractors from the

Office of Scientific and Technical Information

P.O. Box 62, Oak Ridge, TN 37831

Prices available from (423) 576-8401

http://apollo.osti.gov/bridge/

Available to the public from the National Technical Information Service

U.S. Department of Commerce 5285 Port Royal Rd., Springfield, VA 22161 http://www.ntis.gov/

OR

Lawrence Livermore National Laboratory Technical Information Department's Digital Library http://www.llnl.gov/tid/Library.html 
Paper ID: TP.I-01I

\title{
Overview of Chamber and Target Technology R\&D for Heavy Ion Fusion*
}

\author{
Wayne R. Meier
}

Lawrence Livermore National Laboratory, P.O. Box 808, L-446, Livermore, California 94551 USA

\begin{abstract}
In 1999, the Department of Energy's (DOE) Office of Fusion Energy Sciences (OFES) added an inertial fusion energy (IFE) element to its Virtual Laboratory for Technology (VLT). The scope of the IFE element of the VLT includes the fusion chamber, chamber/driver interface, target fabrication and injection, and safety and environmental assessments for IFE. Critical issues have been identified and an integrated R\&D plan for the next 4-5 years has been written to coordinate the research in these areas. This paper provides an overview of the U.S. research activities addressing the critical issues.
\end{abstract}

Keywords: Fusion; Heavy Ion; Inertial fusion; Chambers; Targets

Send proofs to:

Wayne Meier

Lawrence Livermore National Laboratory

P.O. Box 808, L-446

Livermore, CA 94551 USA

Phone: $925-422-8536$

Fax: 925-422-7390

Email: meier5@llnl.gov

* This work was performed under the auspices of the U.S. Department of Energy by the University of California, Lawrence Livermore National Laboratory under Contract No. W-7405-Eng-48. 
Paper ID: TP.I-01I

\section{Introduction}

Support for IFE within the U.S. Department of Energy grew substantially in 2000. The majority of the OFES funded work is being devoted to R\&D on heavy ion drivers, but nearly $20 \%$ is being devoted to the chamber and target technologies for both heavy ion and laser drivers. (Research on high-average-power lasers, which are potential IFE drivers, is currently funded by DOE Defense Programs.) Previous IFE power plant conceptual design studies identified many different driver/chamber/target options and the critical technical issues associated with them. For heavy-ion drivers, current R\&D in the U.S. is primarily focused the renewable, thick-liquid-wall chamber (e.g., HYLIFE-II and modifications [1]) with indirectdrive targets. The top-level critical issues for this approach are summarized here:

1. Chamber Clearing: Will vapor condensation, droplet clearing and flow recovery occur fast enough to allow pulse rates of $\sim 5 \mathrm{~Hz}$ ?

2. Driver/Chamber Interface: Can superconducting final focusing magnet arrays be designed consistent with chamber and target solid angle limits for the required number of beams, standoff distance to the target, magnet dimensions and neutron shielding thickness?

3. Safety and Environment: Can a level of safety be achieved consistent with no-publicevacuation-plan requirement $(<1$ rem site boundary dose) for credible accident temperature excursions and liquid coolant spills?

4. Target Fabrication and Injection: Can hohlraums with internally mounted cryogenic fuel capsules be mass manufactured with the required target precision at a cost less than 0.3 U.S. dollars each? Can these targets withstand the acceleration during injection? Can they be injected, tracked and shot with sufficient accuracy and reliability?

Lawrence Livermore National Laboratory, in conjunction with other laboratories, universities and industry, has written an R\&D plan to focus on these critical issues over the next 4-5 years in a coordinated manner [2]. While all these issues will not be resolve during Phase-I R\&D, the objective is to make significant progress in the resolution and show that credible pathways to resolution exist. Phase-I research will include assessment studies, small-scale experiments, and simulations. Later research will demonstrate more integrated but still non-nuclear tests at closer to full fusion chamber scale. Information developed in Phase-I on chamber and target technologies, advances in driver designs and technology, and evolving target physics requirements for high gain, will be explored with integrated systems analysis in order to assess the overall feasibility and attractiveness of IFE. The small-scale experiments and integrated systems analysis may suggest alternative solutions to the indirect-drive and direct-drive approaches to IFE discussed above.

Activities in the U.S. that have begun to address these issues (including work at UC Berkeley, UCLA, UC San Diego, Georgia Institute of Technology, the University of Wisconsin, General Atomics, Lawrence Livermore National Laboratory, Los Alamos National Laboratory, and the Idaho National Engineer and Environmental Laboratory) will be reviewed.

\section{Chamber Technologies}

Chamber technology R\&D is currently focused on thick-liquid-wall chambers such as HYLIFE-II. In addition to concept development activities, several small-scale experiments on the characteristics of liquid jets are being conducted at UC Berkeley [3,4], UCLA [5], and 
Georgia Institute of Technology [6]. Two basic types of jet flow are required: 1) oscillating jets to form the thick liquid pocket around the target every pulse, and 2) steady-flow, sheet-jets that are arranged to form an array of ports for beam entry. The primary goals of these experiments are to 1) demonstrate that the liquid jet configurations required for the HYLIFE-II chamber can be established, 2) improve the quality of steady flow jets, and 3) demonstrate that the jet configuration can be re-established between pulses.

All three universities experiments have worked on steady flow jets and means of improving jet quality through nozzle design and flow conditioning. Georgia Tech has also produce oscillating sheet jets that move in a pattern required by HYLIFE-II. The work at Georgia Tech is currently focused on characterizing and reducing surface ripple of the beam port jets using high Reynolds number water jets. This is important because the closer the jets can be positioned to the beam path, the more effective the neutron shielding will be. UCLA has been working with a low melting temperature $\left(47^{\circ} \mathrm{C}\right)$ liquid metal ( $\mathrm{Bi}-\mathrm{Pb}-\mathrm{In}-\mathrm{Sn}-\mathrm{Cd}$ mixture). They have investigated the effects of nozzle design on jet quality and are using detailed numeric simulations to predict flow features such as surface waves induced by orifice features. UC Berkeley has demonstrated the type of oscillating jet configuration required to form the protective pocket around the target. Figure 1 shows a steady flow jet and oscillating jet produced in the UCB flow facility [3]. Future work at UCB will utilize a series of chemical detonations to repeatedly disrupt a jet or jet array and then characterize the recovery [4].

The University of Wisconsin is also involved in chamber research for IFE. Their focus is on chamber dynamics modeling for both liquid and dry-wall chambers. Experiments are being proposed on Sandia National Laboratories' Z-machine to examine vaporization of candidate first wall materials (including Flibe) to help validate the various codes used to model chamber dynamics [7].

\section{Chamber/Driver Interface}

The interface of the driver beams with the chamber present several challenges, particularly with current driver designs that have 100 beams or more. Figure 2 illustrates the liquid jets for chamber and beam port protection. This integration requires meeting constraints imposed by the target design (e.g., the acceptance angle of the beam relative to the target axis), the liquid wall shielding configuration, and heating and activation of the final focus magnets. The configuration of the shielding jets is given in [8]. The better the quality of the crossed shielding jets, the closer they can be position to the beam path and the more effective the radiation shielding will be. LLNL is leading efforts to continually integrate these and other power plant subsystems as new information on target and driver requirements become available [9].

Protecting the final focus magnets from radiation damage and heating is another important issue that is being addressed. A detailed 3D analysis of the final focus magnets and shielding (see Figure 3) has been completed [10]. This is preliminary work, and the design has not been optimized. The results indicate the more work is need extend the projected life of the magnets. Magnet heating does not appear to be a major concern. Future work will evaluate the effectiveness of additional shielding between the chamber and magnets, additional bore shielding, and various shield compositions. There is a trade-off here between the design for many beams to reduce the driver cost [11] and the resulting reduction of space available for shielding. Another trade-off is that we would like to position the magnets close to the target to 
improve the ability to focus to small spot size, but this increases the radiation damage rates to the magnets.

\section{Safety and Environmental}

Currently two national labs, INEEL and LLNL lead the safety and environmental (S\&E) work for IFE. Over the past year the codes that were developed to carry out safety analyses for magnetic fusion energy (MFE) power plants have been adapted to study IFE. In these proceedings, the first safety analysis of HYLIFE-II using these adapted models is present [12]. Figure 4 shows the temperature of the first structural material as a function of time after a loss of coolant accident. Note that the temperature rise is quite small; it is only a few tens of degrees. The results of the safety analysis are quite encouraging, giving a site boundary dose of 0.6 rem for a severe accident scenario. This is low enough to avoid the need to have an evacuation plan for the plant, which is one of the goals of the S\&E work.

Another recent activity has been a survey of elements that are most favorable for target fabrication from the point of view of activation. This work is presented in [13]. Some of the best candidates include $\mathrm{Hg}$ and $\mathrm{Pb}$. Both are acceptable from the target physics point of view, with a $\sim 10 \%$ decrease in target gain compared to targets using Au-Gd, a typical high-Z mixture used in target physics calculations. Another important consideration will be the effect that these materials have on the Flibe chemistry. This work has been prospered but is not yet funded [2].

INEEL is planning experiments with Flibe and SnLi, a possible alternative liquid wall candidate. The Fusion Liquid Release Experiment (FLIQUER) will look at mobilization of Flibe constituents that have been exposed to a radiation source. INEEL will also be characterizing the vapor constituents and vapor pressure of both Flibe and SnLi. This information will be used to provide more accurate radioactive source terms for the safety calculations.

\section{Target Fabrication and Injection}

As previously mentioned the key issues here are production of targets at low cost and the ability to inject them without damage to the fragile fuel capsule. This topic is covered extensively in [14] and will not be discussed in any detail here. It is important to note, however, that the target technology area must be closely integrated with the chamber design work. Also, selection of materials for the target must not only be capable of low cost and mass production, but must also be chosen based on S\&E considerations, and in the case of liquid wall chambers, their effect on the chemistry and recovery from the working fluid (Flibe in the case of HYLIFEII). The two principal institutions working in this area are General Atomic (focusing on injection) and Los Alamos National Laboratory (focusing on target materials and fabrication techniques).

\section{Conclusions}

An R\&D plan for IFE chamber and target technologies has been drafted to help coordinate efforts in this area. Current activities are focused on addressing key feasibility issues. Work includes both small-scale experiments and modeling by national laboratories, universities and industry. This work, in combination with success in target physics and driver performance, will 
Paper ID: TP.I-01I

set the stage for proceeding with the next step in the development of heavy ion IFE, which is the Integrated Research Experiment (IRE) [15].

\section{Acknowledgements}

The author would like to acknowledge the contributions of colleagues participating in the IFE chamber and target technology work at General Atomics, Georgia Institute of Technology, Idaho National Engineering and Environmental Lab, Lawrence Livermore National Laboratory, Los Alamos National Lab, UC Berkeley, UCLA, UC San Diego, and the University of Wisconsin.

\section{References}

[1] R.W. Moir, R.L. Bieri, X.M. Chen, T.J. Dolan, M.A. Hoffman, P.A. House, R.L. Leber, J.D. Lee, Y.T. Lee, J.C. Liu, G.R. Longhurst, W.R. Meier, P.F. Peterson, R.W. Petzoldt, V.E. Schrock, M.T. Tobin, W.H. Williams, "HYLIFE-I: A Molten Salt Inertial Fusion Energy Power Plant Design-Final Report," Fusion Technology 25 (1994) 5-25.

[2] W. R. Meier et al., "Chamber and Target Technology Development for Inertial Fusion Energy," LLNL report UCRL-ID-133629 (April 1999).

[3] C. Bauman, S. Pemberton, and P.F. Peterson, "Single-Jet Experiments for HIF Thick-Liquid Chambers," these proceedings.

[4] C. Jansen and P.F. Peterson, "Scaled Impulse Loading for Liquid Hydraulic Response in IFE Thick-Liquid Chamber Experiments," these proceedings.

[5]. A. I. Konkachbaev, N. B. Morley, K. Gulec, and T. Sketchley, "Stability and Contraction of a Rectangular Liquid Metal Jet in a Vacuum Environment," Submitted to the $5^{\text {th }}$ International Symposium on Fusion Nuclear Technology, September 19-24, 1999, Rome, Italy.

[6] Elwell, L. C., Collins, J. A., Yoda, M. and Abdel-Khalik, S. I., "Dynamics of Obliquely Oscillated Turbulent Free Rectangular Jets," American Physical Society Division of Fluid Dynamics Annual Meeting, New Orleans, LA (1999). Bulletin of the American Physical Society 44 (8), 154-155.

[7] R.R. Peterson, "Chamber Dynamics Research with Pulsed Power," these proceedings.

[8] P.A. House, "Focus Magnet and Vessel Interface Issues in HYLIFE-II," Lawrence Livermore National Laboratory report UCRL-ID-137282 (Jan. 2000).

[9] R.W. Moir, "Chamber, Target and Final Focus Integrated Design," these proceedings

[10] J.F. Latkowski and W.R. Meier, "Improved Final Focus Shielding Designs for Modern Heavy-Ion Fusion Power Plant Designs," these proceedings.

[11] W.R. Meier, J.J. Barnard, and R.O. Bangerter, "A 3.3 MJ, Rb ${ }^{+1}$ Driver Design Based on an Integrated Systems Analysis," these proceedings.

[12] S. Reyes, J. F. Latkowski, J. Gomez del Rio, and J. Sanz, "Accident Consequences Analysis of the HYLIFEII Inertial Fusion Energy Power Plant Design," these proceedings.

[13] J.F. Latkowski; "Selection of IFE Target Materials from Recycling and Waste Management Perspectives," these proceedings.

[14] K.R. Schultz and D.T. Goodin, "IFE Target Fabrication and Injection - Achieving Believability," these proceedings.

[15] J.J. Barnard et al., "Planning for an Integrated Research Experiment," these proceedings. 
Paper ID: TP.I-01I
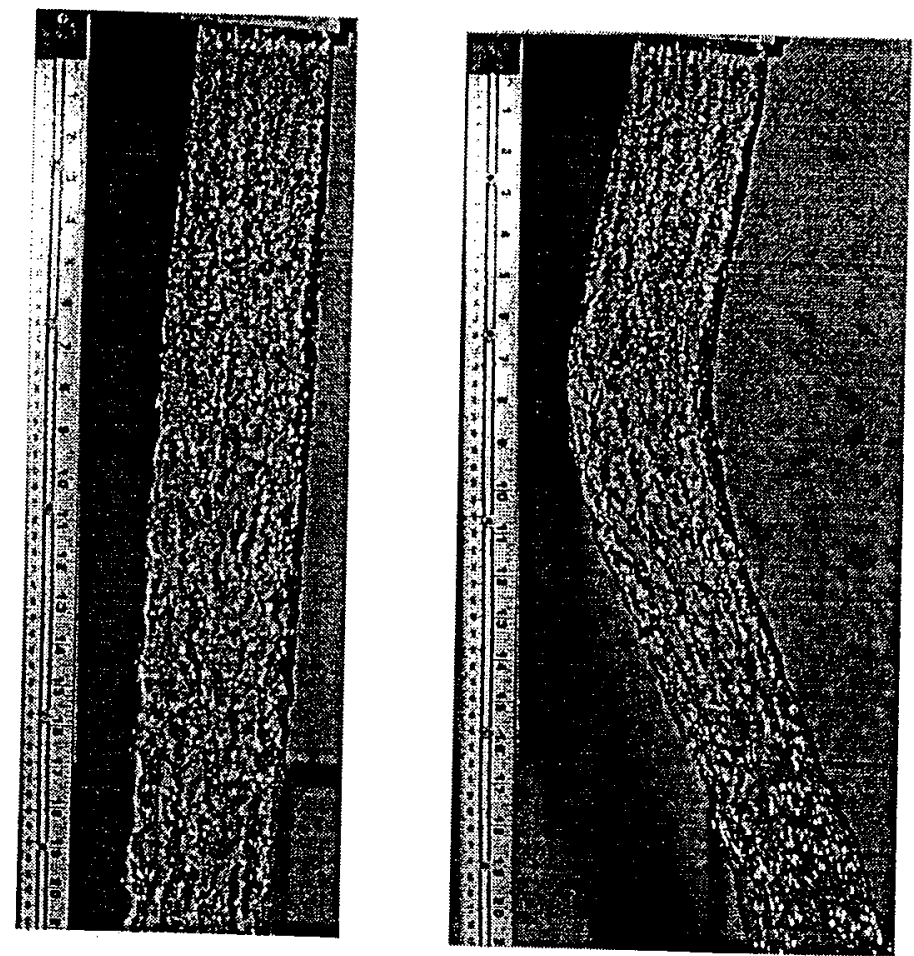

Fig. 1. Stationary (left) and oscillating (right) water jets at the UC Berkeley liquid hydraulic $\mathrm{We}=29,000)$ 


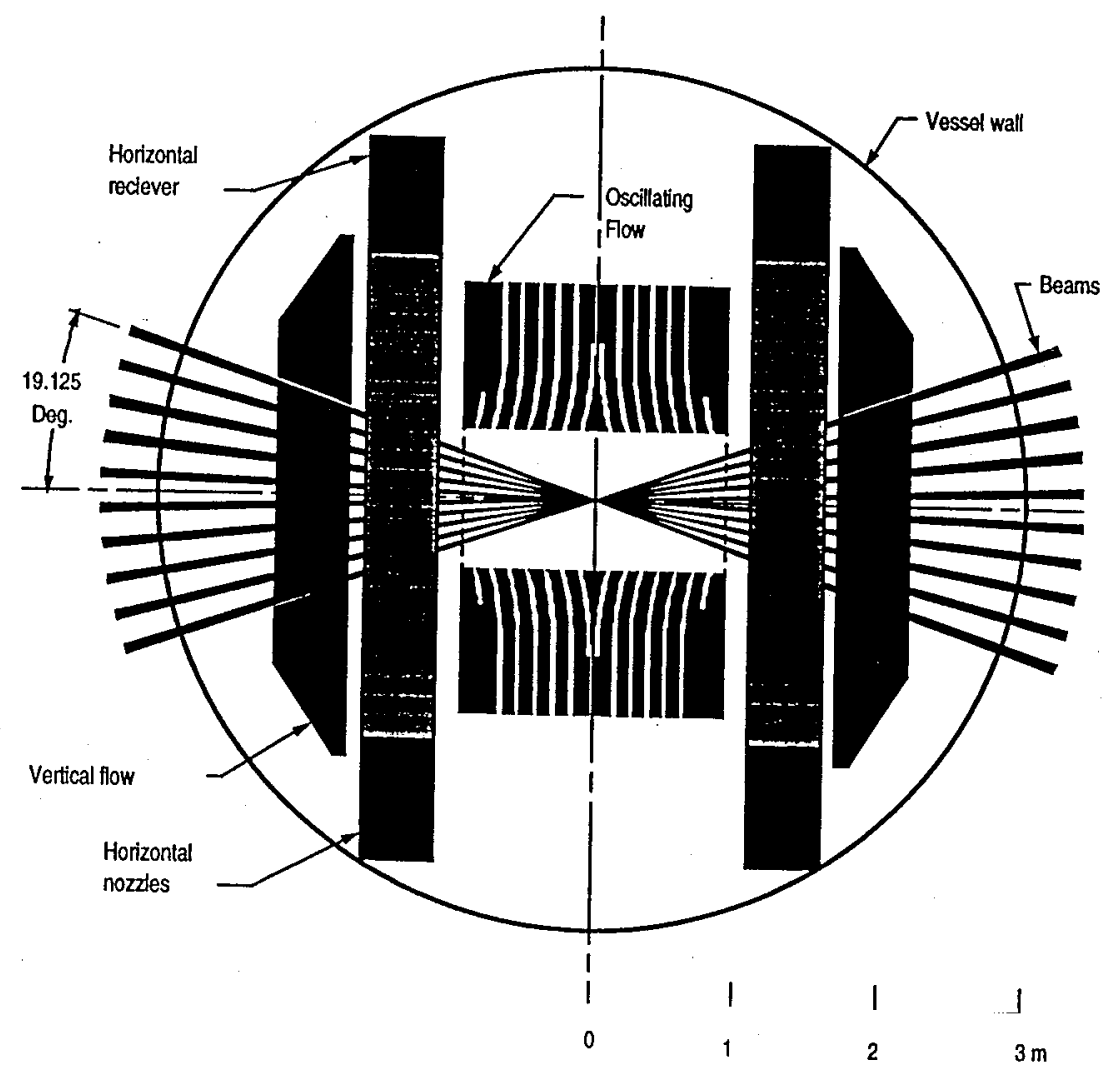

Fig. 2. HYLIFE-I chamber plan view. Oscillating jets surround the target and protect most of the chamber from line-of sight neutrons. Crossing horizontal and vertical jets are used to allow beam entry while shielding the beam port region of the chamber. 
Paper ID: TP.I-01I

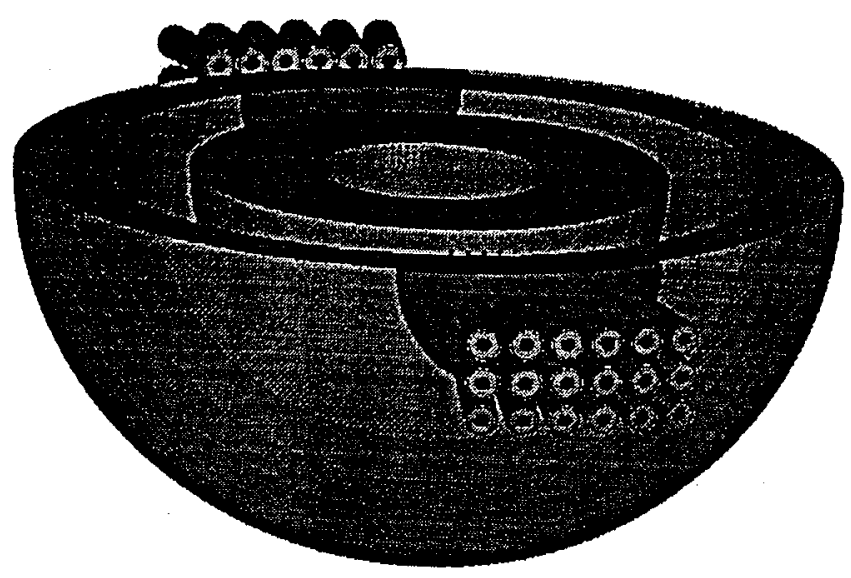
Fig. 3. A three-dimensional neutronics model of the driver/chamber interface was used in the
shielding analyses ( 72 beam case, lower half shown). 


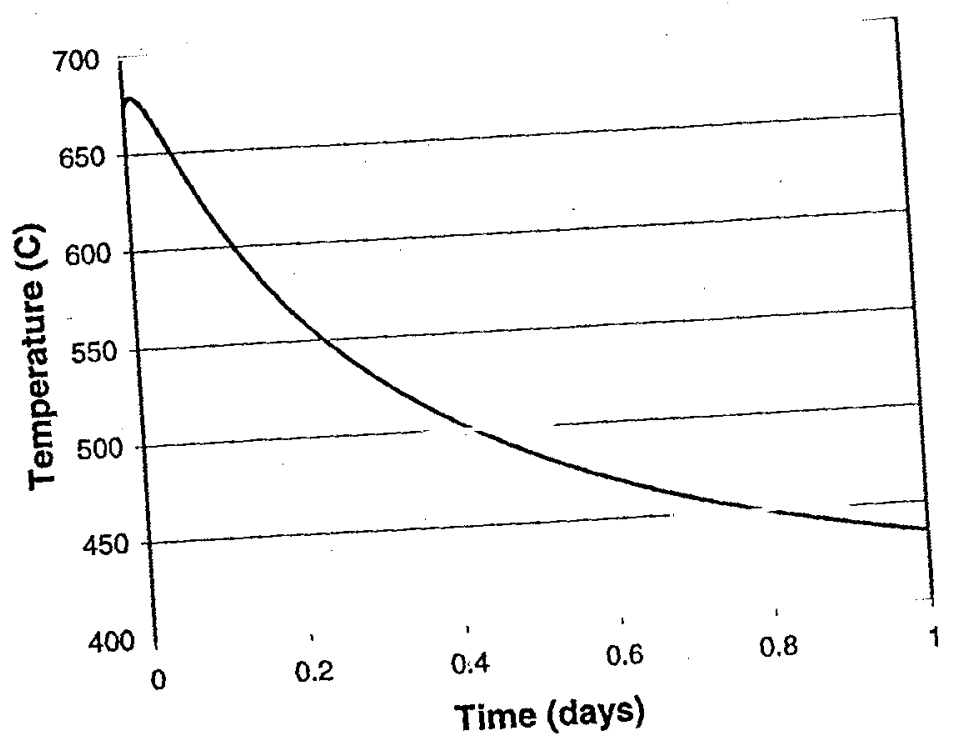

Fig. 4. Temperature evolution in the first wall during the first day following a severe loss of coolant accident. 